\title{
A Summary of Global Routine Immunization Coverage Through 2010
}

\author{
David W. Brown ${ }^{*}, 1$, , Anthony Burton ${ }^{2, \S}$, Marta Gacic-Dobo ${ }^{2, \S}$ and Rouslan Karimov ${ }^{1, \S}$ \\ ${ }^{1}$ UNICEF, New York, New York, USA \\ ${ }^{2}$ WHO, Geneva, Switzerland
}

\begin{abstract}
This brief report summarizes the 2010 revision (July 2011) of the WHO and UNICEF estimates of national routine immunization coverage. In spite of improvements in immunization coverage (DTP3: 74\% during 2000 vs 85\% during 2010; MCV: $72 \%$ during 2000 vs $85 \%$ during 2010), the benefits of vaccination continue to elude many of the world's children suggesting the need for a renewed commitment and investment in routine immunization programmes worldwide.
\end{abstract}

Keywords: Immunization coverage, statistics, immunization, monitoring.

The annual collection and review of national immunization coverage data plays an important role in further reducing the morbidity, and mortality associated with vaccine-preventable diseases and is critical to evaluating progress toward the Global Immunization Vision and Strategy (GIVS). The GIVS, a framework for protecting children from preventable childhood diseases such as measles, tetanus, and whooping cough, calls for raising global immunization coverage for these common diseases to at least 90 per cent in every country over the next five years - a challenge that must be addressed if the world is to achieve the Millennium Development Goal (MDG) of a two thirds reduction in mortality among children under five by 2015. ${ }^{1}$ Each year since 2000, the United Nations Children's Fund (UNICEF) and the World Health Organization (WHO) have jointly reviewed, prepared and published estimates of national immunization coverage for selected "vaccinepreventable" diseases. This report summarizes the 2010 revision (July 2011) of the WHO and UNICEF estimates of national routine immunization coverage made for each of 194 countries and territories. Coverage data are available online at www.childinfo.org/immunization.html and www.who.int/immunization_monitoring/data/en/index.html.

The WHO recommends that all children receive one dose of bacille Calmette-Guérin vaccine (BCG), three doses of diphtheria-tetanus-pertussis vaccine (DTP), three doses of either oral polio vaccine (OPV) or inactivated polio vaccine (IPV), three doses of hepatitis B vaccine (HebB3), and one dose of a measles containing vaccine (MCV). ${ }^{2}$ Since 2000 , WHO and UNICEF have jointly reviewed reports by national authorities regarding national immunization coverage for these and other antigens as well as survey data from the published and grey literature. Based on these data, with due consideration to potential biases and the views of

Address correspondence to this author at the Three United Nations Plaza, New York, NY 10017, USA; Tel: +1.212.303.79.88;

E-mail: dbrown@unicef.org

${ }^{\S}$ The WHO and UNICEF Working Group for Estimates of National Routine Immunization Coverage. local experts (primarily national immunization system managers and WHO/UNICEF regional and national staff), WHO and UNICEF jointly estimate the most likely immunization coverage levels for each country or territory. A more detailed explanation of the estimation methods is provided elsewhere. ${ }^{3}$ It is important to emphasise that while the WHO and UNICEF estimates are informed by data from national authorities and may not differ from official government reported data, they constitute an independent technical assessment by WHO and UNICEF of national routine immunization system performance.

In this report, we present data on global and regional coverage for BCG, first and third dose of DTP (DTP1, DTP3), third dose of polio (Pol3), third dose of HebB (HebB3), third dose of Haemophilus influenzae type B (Hib3) vaccine and first dose of MCV during 2000, 2005 and 2010. We also report global DTP3 coverage from 1980 as well as the estimated number of children unimmunised with three doses of DTP. Immunization coverage levels are presented as the percentage of a target population that has been vaccinated. For example, DTP3 coverage is calculated by dividing the number of children receiving the third dose of DTP vaccine by the number of children who survived to their first birthday. It is important to emphasize that the WHO and UNICEF estimates of national immunization coverage refer to immunizations given during routine immunization services to children less than 12 months of age where such services are recorded; not included are supplementary immunization activities such as polio, tetanus and measles campaigns. The WHO and UNICEF estimates are not the result of a formal modelling exercise and no statistical or mathematical models are used with two exceptions. Coverage for the first dose of DTP vaccine is based on the result of a simple ordinary least squares model of the relationship between DTP1 and DTP3 in those instances where DTP1 data are missing or where a country reports DTP1 coverage below DTP3. The second exception concerns protection-at-birth, which was based on modelled results until $2009 .^{4}$ While there are frequently general trends in immunization coverage levels, no attempt is made to fit data points with smoothing techniques or time series 
methods though the estimation process does allow for interpolation within the time series and extrapolation at the end of the time series.

Global and regional averages are obtained by multiplying the country-specific coverage and a population weight for each country whereby the weight is the country-specific proportion of the global (or regional) total population. The estimated number of births and surviving infants for each country is obtained from the United Nations Population Division. ${ }^{5}$ The number of children unreached with DTP3 is obtained by multiplying the value $(1-$ coverage level; e.g., 0.85 ) for each country and the estimated number of surviving infants for each country obtained from the United Nations Population Division.

Global averages for BCG, DTP1, DTP3, Pol3, HepB3, Hib3 and MCV coverage during 2000, 2005 and 2010 are shown in Table 1. Our review of national routine immunization coverage estimates demonstrates substantial progress has been made since 2000. Globally, DTP3 coverage was $85 \%$ during 2010 , an increase from $74 \%$ during 2000. Similarly, global MCV coverage increased from $72 \%$ during 2000 to $85 \%$ during 2010 . Improvements in coverage were also observed among the developing or least developed countries since 2000 (data not shown). Among 137 developing or least developed countries during 2000, 54 countries attained DTP3 coverage $>90 \%$ (average DTP3 coverage for developing countries, $75 \%$; for least developed countries, 61\%) and 50 countries attained MCV coverage $>90 \%$ (average MCV coverage for developing countries, 73\%; for least developed countries, 59\%); by 2010, 80 of 138 developing or least developed countries reached 90\% DTP3 coverage (average DTP3 coverage for developing countries, $85 \%$; for least developed countries, $80 \%$ ) and 76 countries reached $90 \%$ MCV coverage (average MCV coverage for developing countries, $86 \%$; for least developed countries, $78 \%$ ) (note: developing and least developed country classification based on classifications used by the United Nations in the World Economic Social Survey 2011, available online at www.un.org/en/develop ment/desa/ policy/wess/ ).

Although there have been enormous and increasingly successful efforts to address the global burden of vaccinepreventable diseases and to improve immunization coverage, opportunities remain to improve routine immunization coverage globally. The benefits of vaccination continue to elude many of the world's children; in fact, an estimated 19.3 million infants, or 150 per 1000 surviving infants, were unimmunized with three doses of DTP during 2010 (Fig. 1). While global coverage with three doses of DTP has improved greatly since the 1980s (Fig. 1), improvements at the global level since 2005 have been more modest suggesting the need for a renewed commitment and investment in routine immunization programmes worldwide. The United Nations Children's Fund and the World Health Organization with their partners continue to work with governments to ensure appropriate coordinated and coherent action is taken to improve routine immunization programmes in order to have maximal impact on children's lives.

Table 1. Global and Regional Averages of WHO and UNICEF Estimates of National Routine Immunization Coverage (\%) for Selected Antigens, 2000, 2005, 2010

\begin{tabular}{|c|c|c|c|c|c|c|c|c|c|c|c|c|c|c|c|c|c|c|c|c|c|}
\hline \multirow{2}{*}{$\begin{array}{c}\text { MDG } \\
\text { Region* }\end{array}$} & \multicolumn{3}{|c|}{ BCG } & \multicolumn{3}{|c|}{ DTP1 } & \multicolumn{3}{|c|}{ DTP3 } & \multicolumn{3}{|c|}{ Pol3 } & \multicolumn{3}{|c|}{ MCV } & \multicolumn{3}{|c|}{ НерВ3 } & \multicolumn{3}{|c|}{ Hib3 } \\
\hline & 2000 & 2005 & 2010 & 2000 & 2005 & 2010 & 2000 & 2005 & 2010 & 2000 & 2005 & 2010 & 2000 & 2005 & 2010 & 2000 & 2005 & 2010 & 2000 & 2005 & 2010 \\
\hline $\begin{array}{l}\text { Sub-Saharan } \\
\text { Africa }\end{array}$ & 69 & 74 & 84 & 69 & 75 & 85 & 55 & 65 & 77 & 54 & 66 & 79 & 55 & 63 & 75 & $<10$ & 39 & 74 & $<10$ & 17 & 61 \\
\hline $\begin{array}{l}\text { Northern } \\
\text { Africa }\end{array}$ & 97 & 97 & 98 & 97 & 97 & 98 & 95 & 96 & 97 & 95 & 96 & 97 & 93 & 95 & 96 & 68 & 95 & 97 & $::$ & $<10$ & 41 \\
\hline Western Asia & 92 & 87 & 86 & 92 & 91 & 92 & 84 & 84 & 86 & 85 & 85 & 87 & 85 & 83 & 85 & 67 & 82 & 85 & $<10$ & 38 & 71 \\
\hline $\begin{array}{l}\text { Caucasus \& } \\
\text { Central Asia }\end{array}$ & 96 & 88 & 94 & 95 & 96 & 96 & 93 & 93 & 94 & 94 & 94 & 94 & 93 & 94 & 94 & 24 & 89 & 92 & $::$ & $::$ & 81 \\
\hline Eastern Asia & 84 & 86 & 99 & 94 & 95 & 99 & 85 & 87 & 99 & 87 & 87 & 99 & 84 & 87 & 99 & 60 & 85 & 99 & $::$ & $::$ & $::$ \\
\hline $\begin{array}{l}\text { South-Eastern } \\
\text { Asia }\end{array}$ & 88 & 88 & 95 & 90 & 89 & 93 & 80 & 82 & 88 & 81 & 85 & 92 & 81 & 84 & 91 & 41 & 67 & 87 & & $<10$ & 17 \\
\hline $\begin{array}{l}\text { Southern } \\
\text { Asia }\end{array}$ & 76 & 83 & 88 & 74 & 81 & 86 & 65 & 72 & 77 & 66 & 64 & 76 & 59 & 69 & 78 & $<10$ & 23 & 52 & $::$ & $::$ & 21 \\
\hline Oceania & 83 & 76 & 81 & 86 & 82 & 82 & 65 & 66 & 62 & 56 & 57 & 66 & 66 & 66 & 59 & 64 & 67 & 62 & $<10$ & 10 & 60 \\
\hline Caribbean & 85 & 88 & 88 & 88 & 91 & 92 & 73 & 78 & 79 & 73 & 80 & 79 & 76 & 77 & 76 & 41 & 58 & 56 & 24 & 58 & 54 \\
\hline $\begin{array}{l}\text { Latin } \\
\text { America }\end{array}$ & 97 & 97 & 96 & 97 & 97 & 97 & 92 & 94 & 94 & 93 & 94 & 94 & 94 & 94 & 94 & 67 & 90 & 93 & 72 & 94 & 94 \\
\hline Developed & 92 & 93 & 95 & 97 & 98 & 98 & 93 & 96 & 95 & 94 & 95 & 95 & 92 & 94 & 94 & 50 & 70 & 72 & 61 & 66 & 73 \\
\hline Global & 81 & 84 & 90 & 83 & 87 & 91 & 74 & 79 & 85 & 75 & 77 & 86 & 72 & 78 & 85 & 30 & 54 & 75 & 13 & 21 & 42 \\
\hline
\end{tabular}

Source: WHO and UNICEF estimates of national routine immunization coverage, 2010 data revision (July 2011).

* Millennium Development Goal Region, available at http://www.un.org/millenniumgoals/index.shtml. 


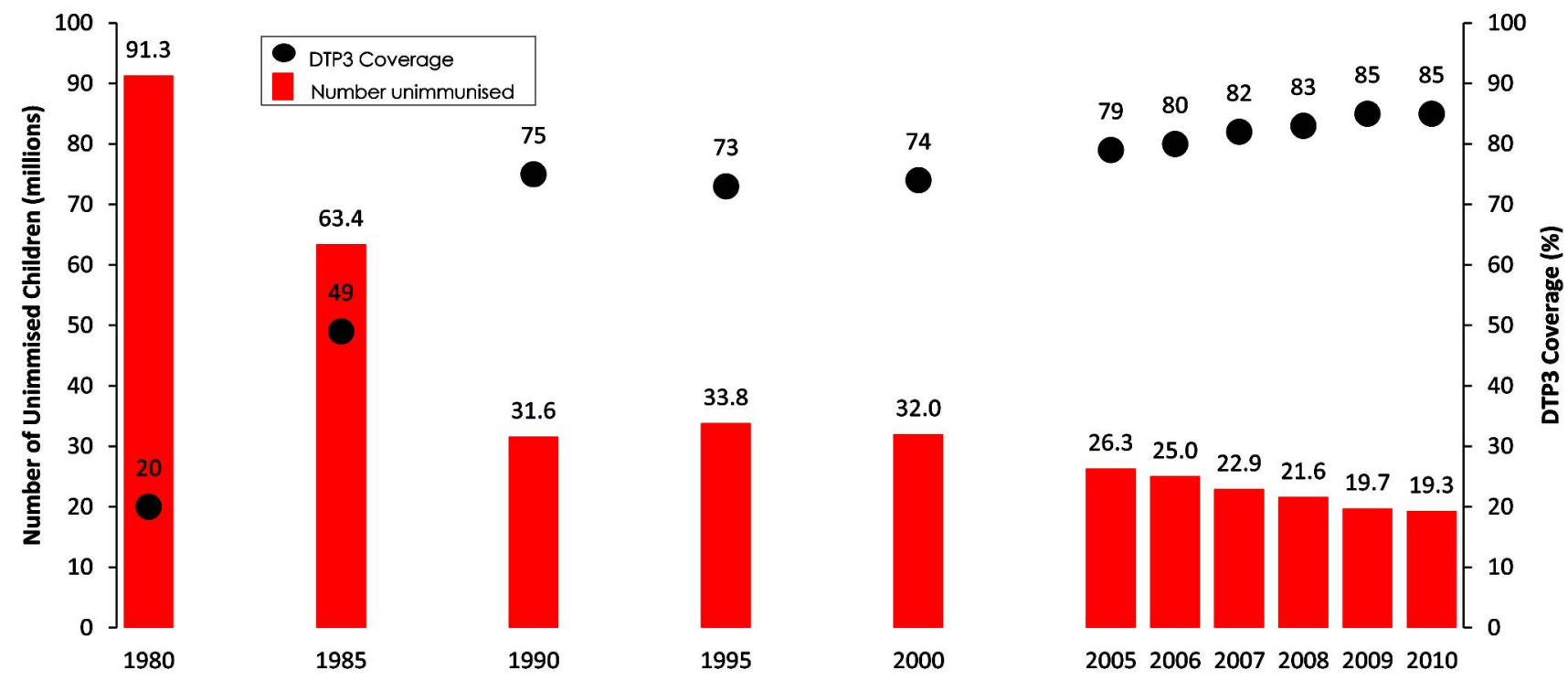

Source: WHO and UNICEF estimates of national routine immunization coverage, 2010 data revision (July 2011); Population data for surviving infants obtained from United Nations, Department of Economic and Social Affairs, Population Division (2011). World Population Prospects: The 2010 Revision, CD-ROM Edition.

Fig. (1). Global routine immunization coverage with three doses of diphtheria and tetanus toxoid with pertussis (DTP3) vaccine among surviving infants and number of surviving infants unimmunised with DTP3, 1980 - 2010.

\section{CONFLICT OF INTEREST}

None declared.

\section{ACKNOWLEDGMENTS}

None declared.

\section{DISCLAIMER}

The findings and views expressed herein are those of the authors alone and do not necessarily reflect those of their respective institutions.

\section{REFERENCES}

[1] Bilous J, Eggers R, Gasse F, et al. A new global immunization vision and strategy. Lancet 2006; 367: 1464-6.

[2] World Health Organization. WHO recommendations for routine immunization - summary tables. Available from http://www.who. int/immunization/policy/immunization_tables/en/
[3] Burton AH, Monasch R, Lautenbach B, et al. WHO and UNICEF estimates of national infant immuniza-tion coverage: methods and processes. Bull World Health Organ 2009;87:535-41.

[4] Griffiths U, Wolfson L, Quddus A, Younus M, Hafiz R Incremental cost-effectiveness of supplementary immunization activities to prevent neo-natal tetanus in Pakistan. Bull World Health Organ 2004;82:643-51.

[5] United Nations, Department of Economic and Social Affairs, Population Division (2011). World Population Prospects: The 2010 Revision, CD-ROM Edition.

This is an open access article licensed under the terms of the Creative Commons Attribution Non-Commercial License (http://creativecommons.org/licenses/ by-nc/3.0/) which permits unrestricted, non-commercial use, distribution and reproduction in any medium, provided the work is properly cited. 